\title{
Литература
}

1. Гемазудинов Д.Р., Мочалин А.Ю. Основные направления развития налогового администрирования в условиях налогового мониторинга // Налоговая политика и практика. 2016. № 3. С. 44 - 49.

2. Линовицкий Ю.А. Практика налогового контроля в зарубежных странах // Налоги и налогообложение. 2009. № 11. С. 40 -44.

3. Рашидова 3.К., Султанов Г.С., Казимагомедова З.А., Алиев Б.Х. Налоговое администрирования России и зарубежной практике // Фундаментальные исследования. 2016. № 9-1. С. 187-191.

4. Шешукова Т.Г., Баленко Д.В. Развитие налогового контроля: опыт зарубежных стран // Вестник Пермского университета. 2013. № 3. С. 122 - 128.

Kravchuk Natalya Sergeevna, Master's Student of the Higher School of Business, Southern Federal University (43, st. 23rd line, Rostov-on-Don, 344019, Russian Federation). E-mail: kravchuk.91@inbox.ru

Kachan Lyubov Vyacheslavovna, Master's Student of the Higher School of Business, Southern Federal University (43, st. 23rd line, Rostov-on-Don, 344019, Russian Federation). E-mail: lybashka_kachan@mail.ru

Artemenko Galina Anatolyevna, Candidate of Economic Sciences, Associate Professor of the Department of State, Municipal Finance and Financial Engineering, Higher school of business, Southern Federal University (43, st. 23rd line, Rostov-on-Don, 344019, Russian Federation). E-mail: gartemenko@sfedu.ru

\section{TAX MONITORING: DEVELOPMENT TREND}

\section{Abstract}

The concept of tax monitoring appeared in the tax system relatively recently, in 2015. Its' emergence is caused by the need to manage tax risks and prevent disputes on both sides. In view of this, it is important to develop more advanced methods and areas of work for the completeness and timeliness of tax control.

Keywords: tax control, tax administration, tax monitoring, tax risks, tax audits.

\section{References}

1. Gemazudinov D.R., Mochalin A.YU. Osnovnye napravleniya razvitiya nalogovogo administrirovaniya v usloviyah nalogovogo monitoringa // Nalogovaya politika i praktika. 2016. № 3. P. 44 - 49.

2. Linovickij YU.A. Praktika nalogovogo kontrolya v zarubezhnyh stranah // Nalogi i nalogooblozhenie. 2009. № 11. P. $40-44$.

3. Rashidova Z.K., Sultanov G.S., Kazimagomedova Z.A., Aliev B.H. Nalogovoe administrirovaniya Rossii i zarubezhnoj praktike // Fundamental'nye issledovaniya. 2016. № 9-1. P. 187-191.

4. SHeshukova T.G., Balenko D.V. Razvitie nalogovogo kontrolya: opyt zarubezhnyh stran // Vestnik Permskogo universiteta. 2013. № 3. P. 122 - 128.

\section{ЭЛИТОЛОГИЧЕСКОЕ ИЗМЕРЕНИЕ РАЗВИТИЯ СИСТЕМЫ ОБРАЗОВАНИЯ В КОНТЕКСТЕ СОВЕРШЕНСТВОВАНИЯ ИНСТРУМЕНТАРИЯ ГОСУДАРСТВЕННОЙ КУЛЬТУРНОЙ ПОЛИТИКИ СОВРЕМЕННОЙ РОССИИ}

\author{
Ляхов аспирант кафедры политологии и этнополитики, \\ Андрей \\ Викторович народного хозяйства и государственного управления при Президенте РФ \\ (344002, Россия, г. Ростов-на-Дону, ул. Пушкинская, 70/54). \\ E-mail: goloborodko2009@mail.ru
}

\section{Аннотация}

Статья посвящена проблеме элитологии образования в рамках стратегического развития и обогащения содержательного и технологического обеспечения инструментария совершенствования государственной культурной политики современной России. Осуществляется контент-анализ содержания проблемы, выявляется круг исследований в контексте особенностей развития концепта «элитология образования» в аспекте рефлексии над сущностными смыслами культурной политики государства.

Ключевые слова: элитология образования, система образования, модернизационные процессы, государственная культурная политика, развитие человеческого потенциала, повышение качества политической элиты, культурная идентичность, Россия.

На сегодняшний день в условиях социально-экономического развития страны, в корреляции с диссеминацией совершенно новых, неизвестных ранее угроз и опасностей для российского государства, стабильности общества высокую степень актуальности набирают вопросы, касающиеся уровня развития и качества политической элиты как одного из фундаментов развития системы политического управления. 
В рассматриваемом контексте весьма актуально, на наш взгляд, обращение к работам известного американского исследователя в области политологии и социологии А. Дж. Тойнби, описавшему, в частности, значимость и особенности функционального назначения элит страны: «чтобы доказать свою состоятельность... быть элитой страны, нужно принимать вызов и, стратегически осмыслив положение страны, найти на него эффективный ответ, пережив стадию надлома и не допустив перехода к стадии дезинтеграции и распада» [5, с. 106].

В последнее время в научно-исследовательском сообществе наблюдаются жаркие дискуссии в фокусе проблематики направлений национального развития и «поиска» культурной и цивилизационной идентичности как важнейших векторов развития, детерминирующих в значительной степени обеспечение национальной безопасности. В связи с этим подчеркнем принципиальную важность культурного суверенитета, выступающего в качестве продуктивного ресурса демпфирования рисков и угроз дитеринга культурно-цивилизационной идентичности как ценностной платформы личностного развития представителей управленческой элиты. Разумеется, процесс развития суверенного государства совершенно невозможен без патриотической и профессиональной национальной элиты.

Очевиден тот факт, что сегодня весьма актуальной является задача развития элиты, повышения качества ее функционирования в контексте осмысления «стратегических полей» совершенствования инструментария государственного управления, обеспечения национальной безопасности, развития бизнеса, науки и образования, культуры. Тем не менее, в сегодняшних, сложных и противоречивых условиях социально-экономического развития страны, ситуация складывается несколько иным образом; явно наблюдается тенденция острого дефицита управленческих кадров, осуществляющих функциональность в суверенной государственной политике [2].

В связи с этим, на наш взгляд, одним из наиболее актуальных направлений исследования выступает именно элитология, изучающая особенности становления и воспроизводства российской элиты в контексте функционирования социума и государства.

В современных условиях развития социума, обусловленных кризисными и транзитивными общественно-политическими тенденциями, важным ориентиром и стратегическим вектором повышения жизнеспособности общества и государства (в том числе в контексте ресурсной базы повышения качества политической элиты), выступает образовательная политика, призванная обеспечить развитие человеческого потенциала и формирование предпосылок изменения «картины мира» молодого поколения, склонного в настоящих условиях, в частности, к конформизму, культурно-смысловой индифферентности, гедонизму, цинизму.

Целью данной статьи является изучение элитологического измерения развития образовательной системы в контексте «точек роста» стратегического развития и обогащения контента совершенствования государственной культурной политики современной России.

Среди наиболее известных исследователей элитологического направления отечественной политической науки в корреляции с содержательным базисом нашего исследования особую значимость имеют научные работы, в частности, Ф.М. Бурлацкого, О.В. Гаман-Голутвиной, Т.И. Заславской.

Кроме того, нельзя не акцентировать внимание на деятельности исследовательского центра О.В. Крыштановской, Ростовской научной элитологической школы А.В. Понеделкова, А.М. Старостина и др., Центра элитологических исследований при Пермском государственном техническом университете, Совета Российского общества политологов, исследовательского центра социологического факультета МГУ им. М. В. Ломоносова и пр., занимающихся исследованиями проблемного поля элитологического измерения развития системы образования. Однако, несмотря на наличие широкого диапазона исследовательского интереса к рассматриваемой проблематике, важно подчеркнуть, что остаются нерешенными многие вопросы, затрагивающие не только конкретизацию терминологического аппарата, но и внедрение эффективных механизмов подготовки элит.

Кроме того, не требует дополнительной аргументации тезис о том, что в последнее время высокий уровень заинтересованности в разработке проблем элитообразования прослеживается во многих областях знания: политологии, социологии, психологии и других, что позволяет констатировать «присутствие» элитологических исследований в широком поле фундаментальных и прикладных междисциплинарных коопераций. В данном контексте, мы можем отметить, что «комплексной научной дисциплиной, все более претендующей на самостоятельный статус, является элитология» [1, с. 217 - 218].

Контент-аналитическое исследование развития элитологии образования позволяет говорить о наличии определенного опыта в рассматриваемой сфере, но, вместе с тем, можно констатировать отсутствие устойчивой системы ретроспективного изучения, что, по нашему мнению, несколько осложняет теоретическое осмысление и анализ возможностей внедрения практического опыта 
прошлого в современное образовательное пространство в контексте подготовки элиты в корреляции с совершенствованием инструментария культурной политики на государственном уровне.

Известный исследователь в области политических наук В.П. Ляхов весьма резонно утверждает, «что среди исследователей до сих пор нет единства по поводу определений понятия «элита», часто в научных работах, посвященных данной проблематике, употребляются такие понятия, как лидерство, бюрократия, правящий или политический класс, номенклатура, властвующая элита, правящая элита, что размывает понятие элиты, при этом оно нередко абсолютизируется в отношении к людям, причастным к власти или капиталу [3, с. 228].

Итак, на наш взгляд, весьма целесообразно, в рамках нашего исследовательского поля, акцентировать внимание на рассмотрении проблемных аспектов элитогенеза в контексте актуальных трендов функционирования современного политического дискурса.

Как мы отмечаем выше, в современных условиях факт дефицита качества управленческих кадров довольно «осязаем» и очевиден, при этом, речь идет о представителях элит, которые «отражают» идеологию государственного строительства и опираются на платформу гражданскопатриотических ценностей, направленных в целом на консолидацию и улучшение качества развития российского общества.

Современная элита, в отличие от прошлых исторических периодов, в значительной степени лишена компетенций и способностей формировать и формулировать модели социального поведения для молодого поколения, происходит снижение ее качества, отмечается деградация морального потенциала ее представителей: к сожалению, уровень развития моральных качеств постсоветской элиты невозможно оценить как высокий и, при этом, отнюдь не редким является низкий уровень индивидуального профессионализма. Как следствие, уместно констатировать дефицит компетенций к адаптации к новым реалиям развития мира. Кроме того, одной из проблемных зон выступает роль элит в реализации суверенной политики государства.

Активное внедрение в последние 25-30 лет в различные каналы коммуникации и информационное поле страны контента ценностно-смысловых «особенностей» западного общества во многом привело к десуверенизации России. В связи с этим, «новый» управленческий корпус лишился методологии и знаний, необходимых для реализации политики укрепления многоаспектного суверенитета государства. Наметилась тенденция роста дефицита управленческих кадров, способных мыслить в национальном масштабе, в категориях больших значений: выхолащивание потенциала великих смыслов государства в новом поколении бюрократических работников привело на практике к усилению бюрократического давления на общество, подмене ценностей.

Тем самым, можно констатировать слабость российской политической элиты в духовной сфере, что проявляется в «дефиците» способностей создать государствоцентричный смысловой «фон» развития, систему ценностных ориентаций, объединяющих и вдохновляющих общество на достижение общих целей. Механический перенос в российское общество либеральных ценностей без учета российских традиций и менталитета зачастую, как показывает практика, приводит к отрицательным результатам. Фактором риска является и низкий уровень общей, политической, правовой культуры политической элиты.

Таким образом, можно утверждать, что необходимость углубленного исследования круга вопросов социального и политического характера, посвященного значимости элитологического контента в развитии системы образования, ценностно-патриотическому аспекту функционирования представителей элиты, весьма очевидна.

На наш взгляд, складывающаяся политическая система в России, характеризующаяся довольно высокими показателями динамизма и изменчивости, масштабным развитием транснациональных процессов, влияющих на успешное развитие общества и государства в целом, особую важность приобретает сохранение и приумножение культурного потенциала российского государства. В этом контексте не можем не солидаризироваться с мнением профессора В.Л. Шаповалова, утверждающего, что «глобализация и универсализация не приводит к стиранию различий между государствами и утрате ими своей идентичности, за исключением слабых, зависимых или несостоявшихся государственных образований, не имеющих мощного интеграционного фактора развитой культуры» [7].

В этой связи исследователь К.Е. Федотова справедливо, по нашему мнению, замечает, что потенциал, накопленный культурой, «должен быть дополнен «эффектом развития», предполагающим активное создание и продвижение современных культурных достижений и творческое использование исторического и культурного наследия с применением потенциала современных средств коммуникации, не ограничиваясь при этом какими-либо культурными или возрастными рамками, предлагая современную медийную, культурную и информационную продукцию» [6, с. 51]. 
Важно, на наш взгляд, подчеркнуть, что область культурного контента включает в себя комплекс разнообразных форм человеческого поведения, которые обусловлены системой ценностных платформ социума, в связи с этим, можно интерпретировать понимание культуры не только в контексте важного детерминанта системного развития, определяющего, в частности, социальноэкономический статус страны но, и в роли важнейшего маркера устойчивого развития.

Государственная культурная политика как когнитивно-методологический конструкт, основанный на поиске эффективных механизмов обеспечения национальной безопасности и реализации стратегии повышения жизнеспособности общества и государства, требует, на наш взгляд, вопервых, пересмотра роли политической элиты в развитии общества и государства, во-вторых, разработку способов укрепления позиции взаимодополняющего триалога между элитой, государством и обществом, в-третьих, концентрации внимания в контексте вопросов, касающихся участия власти и общественных институтов, в формировании системы социальной стратификации и становления российской управленческой элиты.

В Стратегии государственной культурной политики отмечается, что, несмотря на множество узаконенных в Российской Федерации факторов культурной политики, государство является важнейшим участником этой сферы отношений. В Стратегии представлены несколько «матриц», которым государство может следовать при разработке и реализации культурной политики: «государство - инвестор, которое ориентируется на эффективность вложений и управленческих решений в ближайшей и отдаленной перспективе, совершенствовании человеческого потенциала как важнейшем ресурсе стратегического развития, а также целевой характер расходов; государство меценат, финансирующее развитие культурной среды преимущественно на «тактических началах», основанных на возможностях (большей частью, весьма ограниченных) «здесь и сейчас» [4].

Таким образом, сфера культуры способствует качественному развитию главного ресурса государства - человеческого потенциала. Без конструктивного диалога между государством и гражданским обществом в сфере культурного образования, без плавной эволюции политической элиты в направлении понимания роли государства как инвестора не будет развития государства.

Итак, на наш взгляд, в последнее время одной из важнейших задач в контексте актуализации вопросов рефлексии над стратегическим векторами развития образовательной политики государства в контексте развития человеческого потенциала является создание благоприятной информационнокультурной среды и мощной духовно-нравственной платформы для формирования и подготовки политической элиты, которая будет руководствоваться в своих действиях патриотическими и гуманистическими принципами, ориентируясь на развитие и саморазвитие в аспекте обеспечения поступательного движения к обогащению и корреляции профессиональной и гражданской идентичностей.

Таким образом, контент-аналитическое исследование позволяет нам сформулировать ряд предварительных выводов:

1. Анализ специфики институционализации вопросов подготовки элиты в контексте конструирования образовательной политики России позволяет констатировать высокую степень их актуальности в аспекте «точек роста» производства человеческого капитала.

2. В последнее время элитология образования выступает одной из важнейших тем в научноисследовательском сообществе постиндустриального мира. Тенденция неуклонного роста уровня активизации научного интереса все в большей степени детерминирует развитие сложной взаимосвязи педагогической и элитологической науки в будущем. Полагаем, ход модернизационных процессов в России будет зависеть, в том числе и от успешного развития элитизации образовательного пространства.

Кроме того, значительный интерес к рассматриваемому полю вопросов в различных исследовательских дискурсах обусловливает необходимость осмысления перспектив создания конфигурации элитного образования в системе общего образования как важнейшей сфере развития для каждой страны, претендующей на повышение роли в экономической, политической и культурной системе в глобальном масштабе.

3. Систему подготовки и формирования политической элиты как важнейшего драйвера развития диалога государства и общества, а также модернизации различного типа общественных отношений, следует рассматривать, на наш взгляд, отнюдь не «в абстрактных контурах», а весьма конкретно. Это важнейшая предпосылка формирования проекта развития страны, осмысление содержательных оснований и «конструкционного материала» которой предусматривает расширение и укрепление ландшафта реальной среды взаимодействия общества и государства.

Смеем предположить, что если в ближайшее время процесс реформирования системы элитообразования не найдет отражение в реальной действительности, то, как следствие, мы можем наблюдать распространение кризисных явлений в контенте производства духовных ценностей, которые обусловят снижение продуктивности ресурсов укрепления жизнеспособности общества и государства. 


\section{Литература}

1. Ашин Г.К., Понеделков А.В., Старостин А.М., Кислицын С.А. Основы политической элитологии. М.: Книжный дом «Либроком», 2013.

2. Багдасарян, В. Э. Культурное просветительство в системе национальной безопасности России [Электронный ресурс]. URL: http://www.cnsr.ru/press-tsentr/analiticheskie-materialy/kulturnoeprosvetitelstvo-v-sisteme-natsionalnoy-bezopasnosti-rossii/ (дата обращения: 05.09.2020).

3. Ляхов В.П., Маросеев И.П., Ляхов А.В., Котишевский К.Н., Казаков М.Б., Брусняк В.С. Современная правящая элита и культура / В сб.: Российская элитология: инновационные ответы на вызовы современного мира: материалы Третьего Всероссийского элитологического конгресса с международным участием 15-16 февраля 2019 г., Ростов-на-Дону. 2019. С. 224 - 237.

4. Стратегии государственной культурной политики на период до 2030 года [Электронный ресурс]. URL: http://static.government.ru/media/files/AsA9RAyYVAJnoBuKgH0qEJA9IxP7f2xm.pdf (дата обращения: 20.09.2020).

5. Тойнби А. Дж. Вызовы и ответы. Как гибнут цивилизации / А. Дж. Тойнби, С. Ф. Хантингтон. М.: Алгоритм, 2016.

6. Федотова К. «Мягкая сила» российской культуры - инструмент внешней политики // Обозреватель: Научно-аналитический журнал. 2017. № 3. С. 48 - 55.

7. Шаповалов В.Л. Репрезентация ценностных ориентиров советского периода в сознании российской молодежи: по результатам социологического исследования / В сб.: Историческое место советского общества. Материалы Всероссийской научной конференции 6 ноября 2015 г. / Под ред. А.Б. Ананченко. М.: МПГУ, 2016. 230 с.

Lyakhov Andrei Viktorovich, Graduate Student of the Department of Political Science and Ethnopolitics, South Russian Institute of Management - branch of Russian Presidential Academy of National Economy and Public Administration (70/54, Pushkinskaya St., Rostov-on-Don, 344002, Russian Federation).

E-mail: goloborodko2009@mail.ru

\section{ELITOLOGICAL DIMENSION OF THE DEVELOPMENT OF THE EDUCATION SYSTEM IN THE CONTEXT OF IMPROVING THE TOOLS OF THE STATE CULTURAL POLICY OF MODERN RUSSIA \\ Abstract}

The article is devoted to the problem of elitism of education in the framework of strategic development and enrichment of content and technological support of tools for improving the state cultural policy of modern Russia. The content analysis of the problem content is carried out, the range of research is revealed in the context of the development of the concept of "elitology of education" in the aspect of reflection on the essential meanings of the cultural policy of the state.

Keywords: educational elitism, educational system, modernization processes, state cultural policy, human development, improving the quality of the political elite, cultural identity, Russia.

\section{References}

1. Ashin G.K., Ponedelkov A.V., Starostin A.M., Kislicyn S.A. Osnovy politicheskoj elitologii. M.: Knizhnyj dom «Librokom», 2013.

2. Bagdasaryan, V. E. Kul'turnoe prosvetitel'stvo v sisteme nacional'noj bezopasnosti Rossii [Elektronnyj resurs]. URL: http://www.cnsr.ru/press-tsentr/analiticheskie-materialy/kulturnoe-prosvetitelstvo-v-sistemenatsionalnoy-bezopasnosti-rossii/ (data obrashcheniya: 05.09.2020).

3. Lyahov V.P., Maroseev I.P., Lyahov A.V., Kotishevskij K.N., Kazakov M.B., Brusnyak V.S. Sovremennaya pravyashchaya elita i kul'tura / V sb.: Rossijskaya elitologiya: innovacionnye otvety na vyzovy sovremennogo mira: materialy Tret'ego Vserossijskogo elitologicheskogo kongressa s mezhdu-narodnym uchastiem 15-16 fevralya 2019 g., Rostov-na-Donu. 2019. P. $224-237$.

4. Strategii gosudarstvennoj kul'turnoj politiki na period do 2030 goda [Elektronnyj resurs]. URL: http://static.government.ru/media/files/AsA9RAyYVAJnoBuKgH0qEJA9IxP7f2xm.pdf (data ob-rashcheniya: 20.09.2020).

5. Tojnbi A. Dzh. Vyzovy i otvety. Kak gibnut civilizacii / A. Dzh. Tojnbi, S. F. Hantington. M.: Algoritm, 2016.

6. Fedotova K. «Myagkaya sila» rossijskoj kul'tury - instrument vneshnej politiki // Obozrevatel': Nauchnoanaliticheskij zhurnal. 2017. № 3. P. 48 - 55.

7. SHapovalov V.L. Reprezentaciya cennostnyh orientirov sovetskogo perioda v soznanii rossijskoj molodezhi: po rezul'tatam sociologicheskogo issledovaniya / V sb.: Istoricheskoe mesto sovetskogo obshchestva. Materialy Vserossijskoj nauchnoj konferencii 6 noyabrya 2015 g. / Pod red. A.B. Ananchenko. M.: MPGU, 2016. 230 p. 